\title{
CONTAMINAÇÃO POR NITROGÊNIO E FÓSFORO DE ÁGUAS DESTINADAS AO CONSUMO HUMANO EM REGIÃO COM INTENSA ATIVIDADE SUINÍCOLA.
}

\author{
CONTAMINATION BY NITROGEN AND PHOSPHORUS OF WATERS DESTINED FOR HUMAN \\ CONSUMPTION IN A REGION WITH INTENSE SWINE ACTIVITY.
}

\section{Eliana Aparecida CADONÁ ${ }^{1}$, Cledimar Rogério LOURENZI ${ }^{2}$, Eduardo Lorensi de SOUZA $^{3}$, Eduarda CARVALHO RAMPINELLI ${ }^{2}$, Marcos Leandro dos SANTOS ${ }^{2}$, Paula Beatriz SETE ${ }^{2}$, Claudio Roberto Fonseca Sousa SOARES ${ }^{2}$ \\ ${ }^{1}$ Universidade Federal de Pelotas. Faculdade de Agronomia Eliseu Maciel, Campus Universitário. Pelotas/RS. Email: cadona.eliana@gmail.com \\ ${ }^{2}$ Universidade Federal de Santa Catarina. Centro de Ciências Agrárias, Florianópolis/SC. Emails: lourenzicr@ gmail.com; eduardacarvalho@gmail.com; marcosleandrors@gmail.com; paulasete@gmail.com; crfsoares@gmail.com \\ ${ }^{3}$ Universidade Estadual do Rio Grande do Sul, Três Passos/RS. Email: elorensi@ yahoo.com.br}

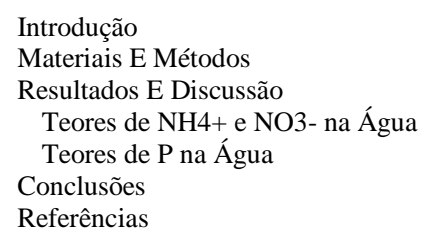

\begin{abstract}
RESUMO - A atividade suinícola na Região Sul do Brasil é desenvolvida em pequenas propriedades, com passivo ambiental relacionados aos dejetos. Nesse sentido, a aplicação de dejetos em áreas agricultáveis, é uma prática comum com riscos potenciais de contaminação, para o solo e a água. Nesse sentido, o objetivo do presente trabalho é avaliar a contaminação por nitrogênio e fósforo de fontes de água destinadas ao consumo humano em região com intensa atividade suinícola no estado de Santa Catarina. Para isso, foram realizadas coletas de água, em poços de abastecimento, em propriedades suinícolas no período de 2015 a 2016, no município de Braço do Norte/SC, além de uma coleta de solo em dezembro/2015. Nas amostras de água foram determinados os teores de $\mathrm{NH}_{4}{ }^{+}, \mathrm{NO}_{3}{ }^{-}$ e formas de $\mathrm{P}$, no solo os teores de $\mathrm{N}$ mineral e $\mathrm{P}$ disponível. A contaminação dos poços de abastecimento por $\mathrm{N}$ aconteceu em duas coletas. Em relação ao $\mathrm{P}$, todos os pontos avaliados apresentam-se contaminados, acelerando a eutrofização. Além disso, há estreita relação entre os teores de $\mathrm{P}$ no solo com os teores observados na água, indicando que o monitoramento dos teores de $\mathrm{P}$ no solo pode ser um excelente indicativo de contaminação de mananciais hídricos.
\end{abstract}

Palavras-chave: Qualidade da água; Dejeto líquido de suínos; Contaminação ambiental.

ABSTRACT - The swine activity in the Southern Region of Brazil is developed in small properties, with environmental liabilities related to the wastes. In this sense, the application of waste in agricultural areas is a common practice with potential contamination risks for soil and water. In this sense, the objective of the present work is to evaluate the contamination by nitrogen and phosphorus of water sources destined for human consumption in a region with intense swine activity in the state of Santa Catarina. For this purpose, water was collected in wells from pig farms during the period from 2015 to 2016, in the municipality of Braço do Norte / SC, in addition to a soil collection in December / 2015. In the water samples, the contents of NH4 +, NO3- and P forms were determined, in the soil the contents of mineral $\mathrm{N}$ and available $\mathrm{P}$. The contamination of the $\mathrm{N}$ supply wells occurred in two collections. In relation to $\mathrm{P}$, all evaluated points are contaminated, accelerating eutrophication. In addition, there is a close relationship between the levels of $\mathrm{P}$ in the soil with the levels observed in the water, indicating that the monitoring of $\mathrm{P}$ levels in the soil can be an excellent indication of contamination of water sources.

Keywords: Water quality; Pig slurry; Environmental pollution.

\section{INTRODUÇÃO}

A suinocultura é uma atividade agropecuária, baseada em um pacote de produção de animais em sistema de confinamento, que está sendo desenvolvida em alguns países através de grandes cadeias de produção. Nesse sentido, a suinocultura apontou como a principal atividade econômica de muitas regiões, especialmente a região sul do Brasil, com destaque para os estados do Rio Grande do Sul e Santa Catarina (Ceretta et al., 2010). Especificamente no Estado de Santa Catarina (SC), esta atividade tem se desenvolvido de maneira mais intensa no Oeste e no Sul do Estado (Gatiboni et al., 2015).
Este sistema suinícola desenvolvido, tem gerado discussões acerca da grande pressão ambiental, pois estes geram grande volume de dejetos, sendo utilizados em áreas agricultáveis, na própria unidade produtora ou em áreas de terceiros, com o intuito de promover uma ciclagem no sistema de produção, bem como, melhoria nas características do solo, em amplo espectro (Guardini et al., 2012). Essa utilização de dejetos em áreas agricultáveis tem apresentado benefícios para o solo, nos aspectos químicos, melhorando a disponibilidade de nutrientes, 
bem como, para os aspectos físicos, melhorando a porosidade e distribuição dos agregados do solo (Pandolfo et al., 2008). No entanto, em doses acima da capacidade de suporte do solo, os processos de percolação e lixiviação de nutrientes e contaminantes podem acelerar-se, ocasionando, além da contaminação do solo, a contaminação de mananciais hídricos superficiais e subterrâneos (Capoane et al., 2015). Visando que, mesmo sendo utilizados como sinônimos, os termos contaminação e poluição apresentam aspectos biológicos diferentes, sendo entendido contaminação como o processo de elevação de algum elemento diferentes das concentrações naturais e a poluição é o aumento que resulta na interferência dos componentes bióticos de um sistema (Alloway, 1995).

Dentre os nutrientes encontrados nos dejetos, o nitrogênio $(\mathrm{N})$ e o fósforo $(\mathrm{P})$ são aqueles encontrados em maiores quantidades e também os que possuem maior potencial para causarem danos ambientais, especialmente, contaminação de mananciais hídricos.

$\mathrm{O} \mathrm{N}$ é um elemento que tem causado problemas ambientais, especialmente em águas de abastecimento urbano subterrâneo (Conceição et al., 2014). Os processos de contaminação por $\mathrm{N}$ têm ocorrido em decorrência de seu ciclo na natureza apresentar complexidade de formas, que passam por processos microbiológicos para a sua utilização no ambiente. $\mathrm{O} \mathrm{NH}_{4}{ }^{+}$quando presente na água causa problemas na disponibilidade de oxigênio aos peixes, causando a morte por asfixia dos mesmos, já que, não conseguem realizar seu processo respiratório, em decorrência as interações do N com a hemoglobina, bem como, pelas alterações histológicas que ocorrem nas brânquias dos peixes, ocasionando a Doença Ambiental das Brânquias (DAB) (Nogueira et al., 2008).

O N aplicado no solo via Dejetos Líquido de Suínos (DLS), apresenta-se potencial risco de contaminação em decorrência, da maior quantidade de $\mathrm{N}$ dos dejetos apresentar-se na forma amoniacal (Basso et al., 2005; Gonzatto et al., 2013) em decorrência da sua forma de armazenamento, que de maneira geral, é realizada em condições de anaerobiose (Pinto et al., 2014) e necessitar de reações de transfor- mações no solo, para tornar-se prontamente disponível no solo, bem como, o $\mathrm{NO}_{3}{ }^{-}$presente no dejeto apresenta grande mobilidade no solo, em especial, fluxo vertical no solo, indicando que, a aplicação de elevadas doses de dejetos em pequenas áreas com frequência relativa, aumenta os processos de lixiviação do $\mathrm{N}$ em profundidade, contami-nando desta maneira, os corpos hídricos subterrâneos.

$\mathrm{O} \mathrm{P}$ é o principal nutriente causador do processo de eutrofização das águas, que pode ocorrer de maneira natural, pelo intemperismo das rochas, porém a principal causa de eutrofização é a ação antrópica em corpos hídricos, principalmente pela erosão de solos e o despejo de efluentes (Santana et al., 2016).

A erosão de solos tem contribuído com as cargas de $\mathrm{P}$ adicionadas aos sistemas aquáticos, em decorrência da prática de correção da fertilidade do solo, através da aplicação de adubos minerais e orgânicos, em especial, os dejetos animais. Neste sentido, a principal forma em que o $\mathrm{P}$ chega aos corpos hídricos é através do escoamento superficial e lixiviação no perfil do solo (Gatiboni et al., 2015).

$\mathrm{O} \mathrm{P}$ adicionado ao sistema aquático induz o processo de eutrofização devido ao maior crescimento de algas que, por sua vez, impedem a passagem da luz solar para dentro dos corpos hídricos e causam a mortandade de organismos bentônicos, que ao serem decompostos consomem oxigênio. O maior consumo de oxigênio por parte dos organismos decompositores, ocasiona a mortandade dos peixes e demais seres aquáticos, que acaba por direcionar a "morte do corpo hídrico", além de ocasionar gosto desagradável a água, em decorrência da alta carga orgânica (Fia et al., 2009; Bucci et al., 2015).

Nesse sentido, torna-se necessário o monitoramento ambiental de regiões com intensa atividade suinícola, para a observação de possíveis cenários de contaminação e de eutrofização dos mananciais hídricos, em decorrência dos efluentes apresentarem-se com elevadas cargas de nutrientes, que podem tornar-se contaminantes (Cucio \& Porto, 2015).

O objetivo do presente trabalho é avaliar a contaminação por nitrogênio e fósforo de fontes de água destinadas ao consumo humano em uma região com intensa atividade suinícola no estado de Santa Catarina. 


\section{MATERIAIS E MÉTODOS}

O trabalho foi desenvolvido na microbacia hidrográfica Rio Coruja/Bonito que possui, aproximadamente, $52 \mathrm{~km}^{2}$ e localiza-se no município de Braço do Norte/SC. O período de avaliação foi de julho de 2015 a junho de 2016, sendo escolhidas quatro propriedades agrícolas na microbacia hidrográfica Rio Coruja/Bonito, sendo três com criação de suínos e uso intensivo de dejetos nas lavouras e uma sem criação de suínos. Neste sentido, para as quatro propriedades estudadas serão avaliados os poços de abastecimento humano.
O clima da região é classificado como subtropical úmido, tipo Cfa, segundo classificação de Köeppen-Geiger, com precipitação pluviométrica e temperatura média anuais de, aproximadamente, $\quad 1.500 \mathrm{~mm}$ e $18,7^{\circ} \mathrm{C}$, respectivamente.

Durante o período de estudo foram obtidos os dados de precipitação e temperatura na Estação Meteorológica do Instituto Nacional de Meteorologia (INMET), localizado no município de Urussanga/SC, os quais são apresentados na figura 1.

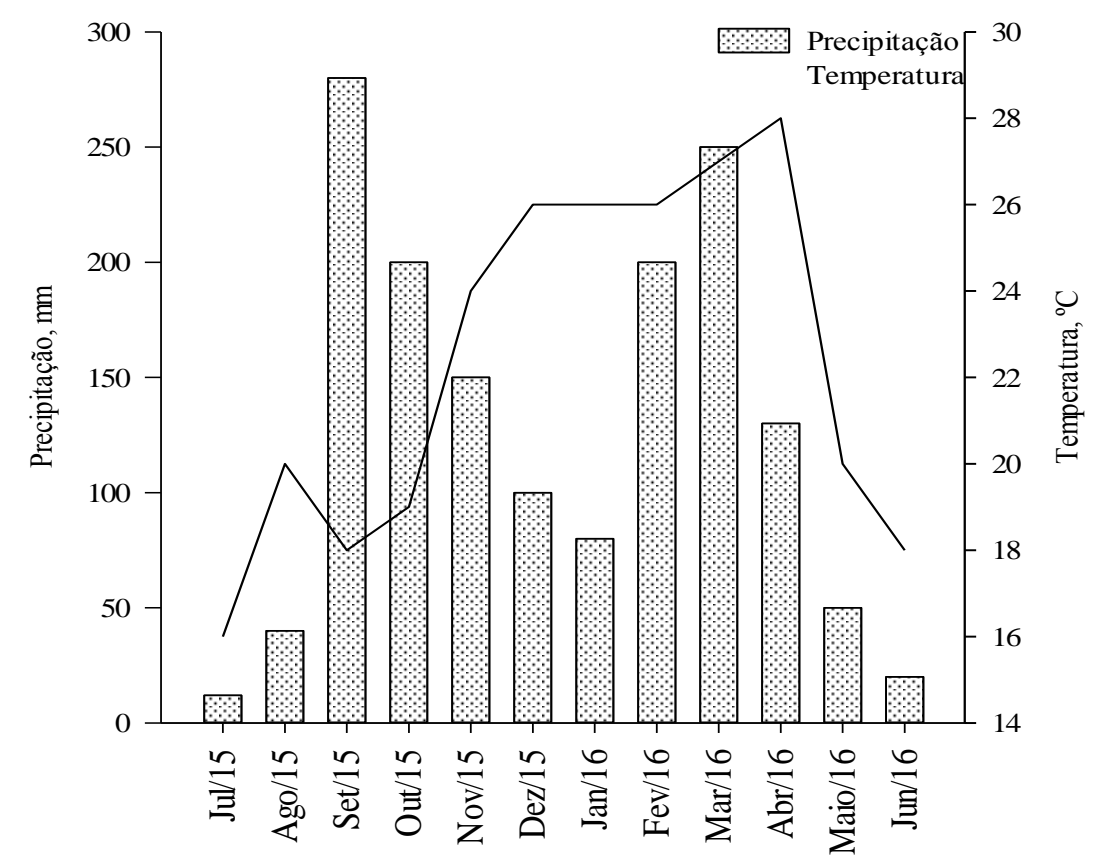

Figura 1 - Precipitação e temperatura média mensal observadas no período de estudo, conforme dados da Estação Meteorológica do INMET, no município de Urussanga/SC.

Para melhor compreensão dos pontos de coleta utilizados para o desenvolvimento do estudo, os mesmos são identificados como PA - poços de abastecimento, sendo: PA1 (latitude 28 13 '992" S; longitude 49०06'201" $\mathrm{O}$; altitude $383 \mathrm{~m}$ ): localizado em propriedade suinícola, adjacente a área agrícola que recebe aplicação de dejetos de suínos, caracteristicamente um poço com aproximadamente 5 metros de profundidade, sem a presença de vegetação nos arredores do mesmo; PA2 (latitude 28 $11^{\prime} 786^{\prime \prime} \mathrm{S}$; longitude 4904'770" $\mathrm{O}$; altitude $405 \mathrm{~m}$ ): encontra-se em propriedade com criação de suínos e gado leiteiro, apresenta profundidade aproximada de 30 metros, localizado próximo a áreas de lavoura, que consistem de pastagem anual para a alimentação do gado leiteiro e monocultivo de milho, no inverno e verão, respectivamente, utilizando-se dos dejetos de suínos; PA3 (latitude 28 $11^{\prime} 818^{\prime \prime} \mathrm{S}$; longitude 4905'492" O; altitude $399 \mathrm{~m}$ ): localizado em propriedade que não possui criação de suínos, porém ocorre criação de gado leiteiro, e o mesmo caracteriza-se por não ser subterrâneo, estando protegido por espécies em regeneração, observando os limites do Código Florestal; PA4 (latitude 28 12 '483" S; longitude $49^{\circ} 05^{\prime} 204^{\prime \prime} \mathrm{O}$; altitude $388 \mathrm{~m}$ ): inserido sob a residência da propriedade, com profundidade aproximada de 5 metros, e com presença de atividade suinícola e bovinocultura de leite.

As coletas de água foram realizadas nos meses de Julho, Outubro e Dezembro de 2015 e Março e Junho de 2016, sendo a $1^{\text {a }}$ coleta realizada em $20 / 07 / 2015$, a $2^{\mathrm{a}}$ em 20/10/2015, a $3^{\mathrm{a}} \mathrm{em}$ 
05/12/2015, a $4^{\text {a }}$ em 21/03/2016 e a $5^{\text {a }}$ em 24/06/2016. Em cada ponto foram coletados, aproximadamente, $300 \mathrm{~mL}$ de água, sendo essas amostras armazenadas em caixa de poliestireno refrigeradas, para posterior análise no Laboratório de Análise de Solo, Água e Tecidos Vegetais do Departamento de Engenharia Rural da Universidade Federal de Santa Catarina (UFSC). No laboratório, aproximadamente, $50 \mathrm{~mL}$ de cada amostra foram filtrados utilizando-se filtros de celulose com diâmetro de poros de $0,45 \mu \mathrm{m}$ e, juntamente com o restante das amostras não filtradas, foram armazenadas em refrigerador com temperatura média de $4^{\circ} \mathrm{C}$. Nas amostras não filtradas foram determinados os teores de $\mathrm{N}$, em sua forma $\mathrm{NH}_{4}{ }^{+}$e $\mathrm{NO}_{3}{ }^{-}$. Para isso foram adicionados $20 \mathrm{~mL}$ de amostra em tubos de digestão, $0,7 \mathrm{~g}$ de $\mathrm{MgO}$ e destilou-se a amostra em destilador tipo Microkjeldahl, sendo o destilado ( \pm $35 \mathrm{~mL}$ ) coletado em recipiente com indicador ácido bórico e titulado com $\mathrm{H}_{2} \mathrm{SO}_{4} 0,0025 \mathrm{~mol} \mathrm{~L}^{-1}$ para a determinação dos teores de $\mathrm{NH}_{4}{ }^{+}$. Posteriormente, na mesma amostra, adicionou-se 0,7 g de Liga de Devarda e destilou-se novamente, sendo o destilado $( \pm 35 \mathrm{~mL})$ coletado em recipiente com indicador ácido bórico e titulado com $\mathrm{H}_{2} \mathrm{SO}_{4} 0,0025 \mathrm{~mol} \mathrm{~L}^{-1}$ para a determinação dos teores de $\mathrm{NO}_{3}{ }^{-}$. Todas as determinações foram realizadas conforme Tedesco et al. (1995).

Para a interpretação dos teores de $\mathrm{NH}_{4}{ }^{+}$, segundo a Resolução CONAMA n³57/2005, existem valores de Nitrogênio Amoniacal Total conforme as faixas de $\mathrm{pH}$ das amostras de água analisadas, nesse sentido os valores de $\mathrm{pH}$ obtidos nos poços de abastecimento no período de estudo são apresentados na tabela 1 .

Tabela 1 - Valores de $\mathrm{pH}$ para os poços de abastecimento avaliados.

\begin{tabular}{c|c|c|c|c|c}
\hline \multirow{2}{*}{ Ponto } & \multicolumn{5}{|c}{ Coleta } \\
\cline { 2 - 6 } & $1^{\mathbf{a}}$ & $2^{\mathbf{a}}$ & $3^{\mathbf{a}}$ & $4^{\mathbf{a}}$ & $5^{\mathbf{a}}$ \\
\hline PA1 & 5,31 & 5,18 & 5,70 & 5,68 & 4,69 \\
\hline PA2 & 6,85 & 5,60 & 5,75 & 5,00 & 4,71 \\
\hline PA3 & 5,74 & 5,20 & 5,90 & 5,36 & 5,45 \\
\hline PA4 & 5,18 & 5,80 & 5,00 & 5,00 & 5,26 \\
\hline
\end{tabular}

Nas amostras filtradas foram determinados os teores de $\mathrm{P}$ solúvel (Ps) em água, de acordo com método proposto por Murphy \& Riley (1962). Além da determinação dos teores de Ps na água, também foram determinados os teores totais de $\mathrm{P}$ (Pt) da água, através de digestão ácida nitroperclórica das amostras não filtradas, segundo metodologia adaptada e descrita por Silva (1999). Os teores de $\mathrm{P}$ particulado (Pp) foram obtidos a partir da subtração dos teores solúveis dos teores totais. Adjacente a cada ponto de coleta de água foi realizada, em dezembro/2015, uma coleta de solo para avaliar a relação entre os teores de $\mathrm{N}$ e $\mathrm{P}$ no solo com os observados nas amostras de água. Para isso, foram abertas trincheiras até $40 \mathrm{~cm}$ de profundidade, com auxílio de uma pá de corte, e coletou-se amostras de solo nas profundidades 05, 5-10, 10-20 e 20-40 cm. A coleta de solo foi realizada nos pontos PA1, PA2 e PA4.
Nas amostras de solo coletadas foram determinados os teores de $\mathrm{N}$ mineral e $\mathrm{P}$ disponível. Os teores de $\mathrm{N}$ mineral foram determinados conforme metodologia descrita por Tedesco et al. (1995), após extração com KCl 1 mol L $\mathrm{L}^{-1}$, destilação em destiladores do tipo Microkjeldahl e titulação com $\mathrm{H}_{2} \mathrm{SO}_{4}$ 0,0025 mol $\mathrm{L}^{-1}$. A extração dos teores de $\mathrm{P}$ disponível foi realizada conforme metodologia descrita por Tedesco et al. (1995) e a determinação no extrato obtido foi realizada por colorimetria (Murphy \& Riley, 1962). Os dados obtidos são apresentados na tabela 2. Os dados obtidos, para a qualidade da água, foram analisados a partir da média e desvio padrão para cada coleta e parâmetro analisado. Para verificar a relação dos teores de $\mathrm{N}$ e $\mathrm{P}$ encontrados no solo com os teores na água, foi realizado teste de correlação de Pearson com 5\% de probabilidade.

Tabela 2 - Teores de N mineral e P disponível no solo em propriedades suinícolas de Braço do Norte/SC.

\begin{tabular}{c|c|c|c|c|c|c}
\hline \multirow{2}{*}{$\begin{array}{c}\text { Profundidade } \\
(\mathbf{c m})\end{array}$} & PA1 & & \multicolumn{2}{|c|}{ PA2 } & \multicolumn{2}{c}{ PA4 } \\
\cline { 2 - 7 } & N min. & P disp. & N min. & P disp. & N min. & P disp. \\
\cline { 2 - 7 } & \multicolumn{5}{|c}{$\mathrm{mg} \mathrm{kg}^{-1}$} \\
\hline $0-5$ & 17,66 & 4,33 & 21,33 & 34,00 & 44,66 & 48,00 \\
\hline $5-10$ & 16,00 & 4,66 & 14,00 & 9,33 & 20,00 & 24,66 \\
\hline $10-20$ & 24,33 & 7,00 & 8,00 & 7,00 & 22,33 & 71,00 \\
\hline $20-40$ & 13,00 & 4,00 & 6,66 & 4,00 & 10,00 & 43,00 \\
\hline Média & 17,75 & 5,00 & 12,50 & 13,58 & 24,25 & 46,66 \\
\hline
\end{tabular}




\section{RESULTADOS E DISCUSSÃO}

\section{Teores de $\mathrm{NH}_{4}^{+} \mathrm{e} \mathrm{NO}_{3}^{-}$na Água}

Para os poços de abastecimento avaliados, observou-se teores variando de $0,35 \mathrm{mg} \mathrm{L}^{-1}$ a $15,17 \mathrm{mg} \mathrm{L}^{-1}$ para $\mathrm{NH}_{4}^{+}$e $0,35 \mathrm{mg} \mathrm{L}^{-1}$ a 16,80 mg $\mathrm{L}^{-1}$ para $\mathrm{NO}_{3}^{-}$(Figura 2). Segundo a Resolução CONAMA no $357 / 2005$, para o parâmetro Nitrogênio Amoniacal Total, o limite é de $3,7 \mathrm{mg} \mathrm{L}^{-1}$ para águas doce com $\mathrm{pH}<7,5$ na classe 2, que são águas destinadas ao abastecimento humano, após tratamento convencional, juntamente com a proteção de comunidades aquáticas, recreação de contato primário, irrigação, aquicultura e a atividade de pesca. Já para o $\mathrm{NO}_{3}^{-}$, a mesma resolução estabelece como limite o valor de $10 \mathrm{mg} \mathrm{L}^{-1}$ para todas as classes de água doce.
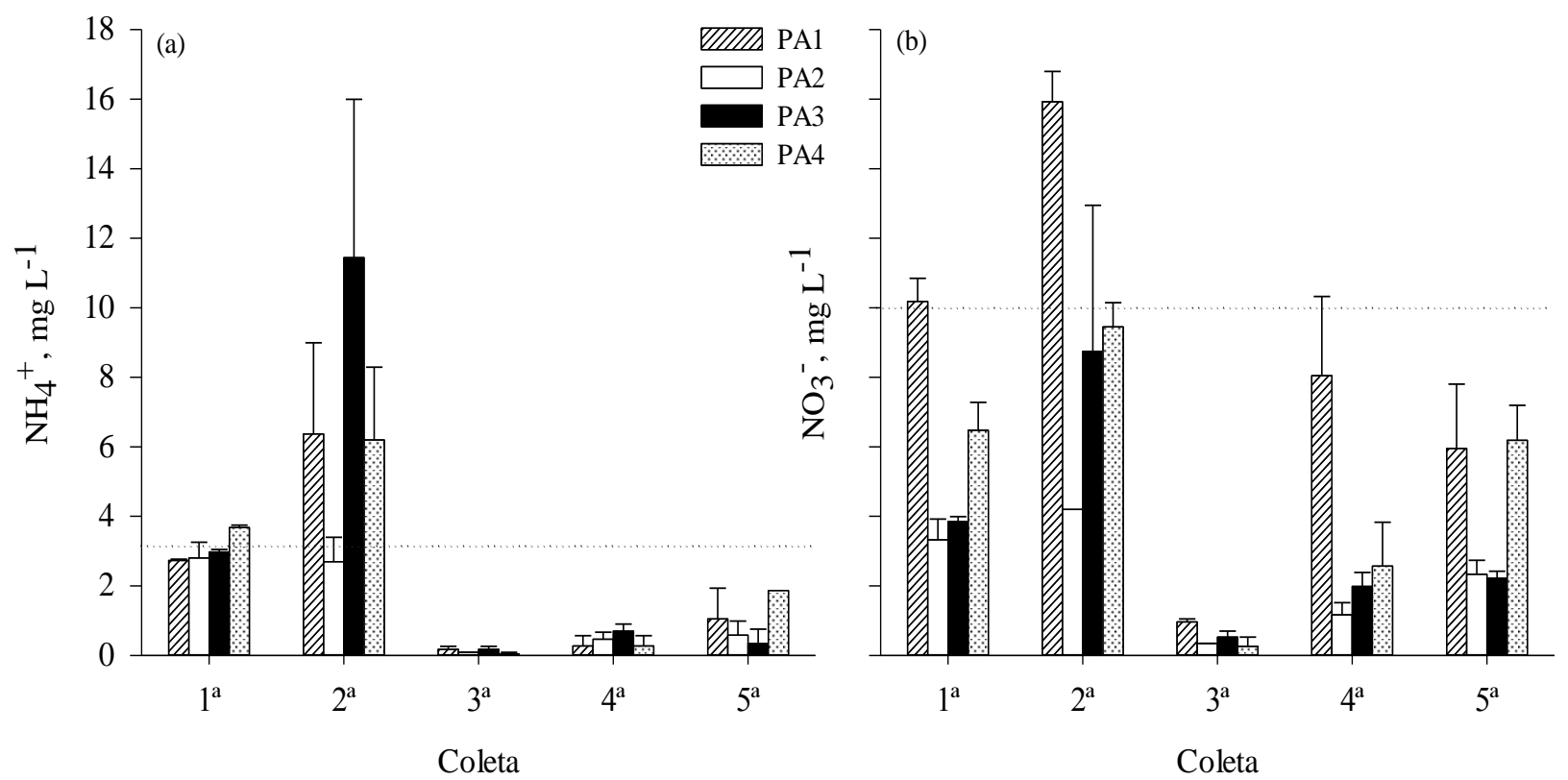

Figura 2 - Teores de $\mathrm{NH}_{4}{ }^{+}$(a) e $\mathrm{NO}_{3}{ }^{-}$(b) em poços de abastecimento em propriedades suinícolas no município de Braço do Norte $/ S C$. $1^{a}$ coleta $=20 / 07 / 2015 ; 2^{a}$ coleta $=20 / 10 / 2015 ; 3^{a}$ coleta $=05 / 12 / 2015 ; 4^{a}$ coleta $=21 / 03 / 2016$; $5^{\mathrm{a}}$ coleta $=24 / 06 / 2016$

Observou-se de maneira geral, que os teores de $\mathrm{NH}_{4}{ }^{+}$e $\mathrm{NO}_{3}{ }^{-}$apresentaram valores próximos, estabelecendo padrão semelhante de comportamento em todos os pontos avaliados e épocas de coleta. Esse comportamento diferencia-se dos dados obtidos por Pontes et al (2012), que avaliaram o efeito do uso e ocupação do solo na qualidade da água num ciclo sazonal em diferentes pontos da microbacia do córrego Banguelo, com o intuito de contribuir para os conhecimentos das características e contribuições das principais fontes de degradação ambiental e de poluição para a microbacia da Pampulha, observaram relação inversa entre os teores de $\mathrm{NH}_{4}{ }^{+}$e $\mathrm{NO}_{3}{ }^{-}$na água. Nesse sentido, os mesmos autores afirmam que, quando não ocorre predomínio de $\mathrm{NH}_{4}{ }^{+} \mathrm{e} \mathrm{NO}_{3}{ }^{-}$ pode estar ocorrendo formas intermediárias como nitrito e amônia, não podendo assim, inferir maiores quadros de contaminação.

Para o parâmetro $\mathrm{NH}_{4}^{+}$, para a $1^{\text {a }}$ coleta (julho/2015) somente o ponto PA4 e para a $2^{\mathrm{a}}$ coleta (outubro/2015), os pontos PA1, PA3 e PA4 apresentaram teores acima do limite estabelecido pela resolução vigente (Figura 2), ficando o ponto PA2 como o único que não apresentou teores acima do permitido para $\mathrm{NH}_{4}{ }^{+}$. Para as coletas de Dezembro/2015, Março/2016 e Junho/2016) para todos os pontos, os teores observados estavam dentro do limite estabelecido em resolução. Dessa maneira, conclui-se que os pontos PA1, PA3 e PA4 apresentaram em algum momento do estudo, poluição por compostos nitrogenados nas águas de consumo humano, especialmente $\mathrm{NH}_{4}{ }^{+}$, e para os demais pontos e coletas estava ocorrendo somente a contaminação das águas.

Atribui-se teores mais elevados de $\mathrm{NH}_{4}{ }^{+}$na $2^{\mathrm{a}}$ coleta, em decorrência dos meses de setembro e outubro apresentarem os maiores índices pluviométricos (Figura 1), com volume aproximado de $300 \mathrm{~mm}$, aumentando o fluxo de 
água no solo e, consequentemente, o carreamento de compostos nitrogenados. Especificamente, para a microbacia do Rio Coruja/Bonito, a aplicação de DLS em áreas agricultáveis é realizada ao longo de todo o ano $\mathrm{e}$, devido o $\mathrm{N}$ apresentar grande mobilidade no solo, sofre grandes transferências para mananciais hídricos, seja por escoamento superficial seja por percolação (Ceretta et al., 2010; Girotto et al., 2013).

Espera-se em solos que recebem aplicação de DLS, ocorra predomínio da forma amoniacal no solo, logo após a aplicação dos mesmos, e eventualmente na água, em decorrência de sua maior presença nos efluentes. Conforme observado por Gonzatto et al. (2013) ao avaliarem as perdas de $\mathrm{N}$ para a atmosfera, em especial, através da volatilização de $\mathrm{NH}_{3}$ e emissão de $\mathrm{N}_{2} \mathrm{O}$ após aplicação de DLS em cultivo de milho, com e sem a presença de resíduos culturais de aveia na superfície do solo, com a aplicação de $60 \mathrm{~m}^{3} \mathrm{ha}^{-1}$ afirmam que, quando os DLS são aplicados com elevada intensidade, ocorre maiores perdas para o ambiente, sendo para a atmosfera como para a água, ocorrendo predomínio das formas amoniacais nos dejetos, que são menos utilizadas pelas plantas em estágios iniciais de desenvolvimento das mesmas, ocasionando maior impacto ambiental.

Para os teores de $\mathrm{NO}_{3}{ }^{-}$, observa-se que o ponto PA1 apresentou teores acima do limite para a $1^{\mathrm{a}}$ (julho/2015) e $2^{\mathrm{a}}$ (outubro/2015) coletas, sendo preocupante pois apresenta quadro de poluição do mesmo, alterando a qualidade da água, de maneira mais direta, e provocando reações adversas nos organismos que a ingerirem. Conforme Conceição et al. (2014), existe relação entre teores de $\mathrm{NO}_{3}{ }^{-}$e a presença de nitrosaminas e nitrosamidas carcinogênicas e mutagênicas, bem como, a incidência de metahemoglobinemia, apresentando grande preocupação para a saúde pública, tornando assim, um problema de ordem ambiental e de saúde pública. Para os demais pontos e coletas não foram observados teores acima do permitido, no entanto, a Companhia Estadual de Tecnologia Ambiental do Estado de São Paulo (CETESB), apresenta teores de $5 \mathrm{mg}$ $\mathrm{L}^{-1}$ de $\mathrm{NO}_{3}{ }^{-}$como indicadores de efluente aos corpos hídricos e a necessidade de medidas mitigatórias e preventivas para que não ocorra aceleração dos processos de contaminação por $\mathrm{N}$.

Os menores teores de $\mathrm{NO}_{3}{ }^{-}$foram obtidos na $3^{\text {a }}$ coleta (dezembro/2015), indicando que, menores precipitações ocasionam diminuição nos teores de $\mathrm{NO}_{3}{ }^{-}$nos meses mais secos, corroborando com Buzelli \& Cunha-Santino (2013), observaram que, os teores de nitrato diminuíram no período de estiagem, indicando que, menores precipitações pluviométricas interferem diretamente nos teores de $\mathrm{NO}_{3}{ }^{-}$, pois a menor fluxo de água no solo com compostos nitrogenados.

Nesse sentido, a presença de $\mathrm{N}$ em suas diferentes formas em corpos hídricos é indicativo de contaminação, sendo que em áreas urbanas, é indicativo de condições higiênicosanitárias insatisfatórias (Silva et al., 2015), e em áreas rurais, é indicativo que além de efluentes humanos, possivelmente efluentes animais estão chegando aos corpos hídricos, juntamente com compostos nitrogenados das adubações em áreas agricultáveis.

Observa-se que, os teores de $\mathrm{N}$ mineral no solo não possuem correlação com os teores de $\mathrm{N}$ na água, conforme a tabela 3. Esse processo é observado devido à grande dinâmica do $\mathrm{N}$ no sistema, pois apresenta elevada mobilidade no solo, sendo facilmente transferido para mananciais hídricos quando da ocorrência de precipitações.

Isso evidencia que, para esse elemento, o manejo dos dejetos em áreas agricultáveis deve ser realizado de forma parcelada e em pequenos volumes, evitando grandes adições de $\mathrm{N}$ ao solo e, consequentemente, reduzindo as transferências por escoamento superficial e percolação.

Tabela 3 - Correlação de Pearson entre os teores de N mineral na água e no solo e os teores de P solúvel na água e P disponível no solo.

\begin{tabular}{l|c|c|c|c}
\hline \multirow{2}{*}{ Parâmetros } & \multicolumn{2}{|c|}{ N mineral água } & \multicolumn{2}{c}{ P solúvel água } \\
\cline { 2 - 4 } & Valor $p$ & $\mathrm{R}^{2}$ & Valor $p$ & $\mathrm{R}^{2}$ \\
\hline N mineral solo & 0,872 & $-0,06$ & - & - \\
\hline P disponível solo & - & - & $<0,0001$ & 0,98 \\
\hline
\end{tabular}

Correlação de Pearson realizada ao nível de 5\% de probabilidade de erro; Para os teores de N mineral e P disponível no solo foi considerada a média das quatro camadas de solo avaliadas. 


\section{Teores de P na Água}

Para os poços de abastecimento avaliados obteve-se variação de $0,07 \mathrm{mg} \mathrm{L}^{-1}$ a $1,42 \mathrm{mg} \mathrm{L}^{-1}$ para os teores de $\mathrm{Pt}(\mathrm{Ps}+\mathrm{Pp})$ (Figura 3). Considerando que a resolução do CONAMA $n^{\circ}$ 357/2005 estabelece, para águas doces de classe 2, o limite de $0,030 \mathrm{mg} \mathrm{L}^{-1}$ de $\mathrm{P}$ total, observa-se que todos os poços apresentam-se contaminados por $\mathrm{P}$, pois ultrapassam os limites estabelecidos pela legislação. Além disso, é importante destacar que há predomínio da forma $\mathrm{Pp}$ para o ponto PA1 e PA2 e da forma Ps para os pontos PA3 e PA4.

Os maiores teores de $\mathrm{P}$ foram observados na $3^{\text {a }}$ coleta (dezembro/2015) na maioria dos pontos avaliados, com predomínio da forma dissolvidas. Além disso, é importante destacar que os menores teores de $\mathrm{P}$ foram observados na $5^{\text {a }}$ coleta (junho/2016), que é justificado pelos
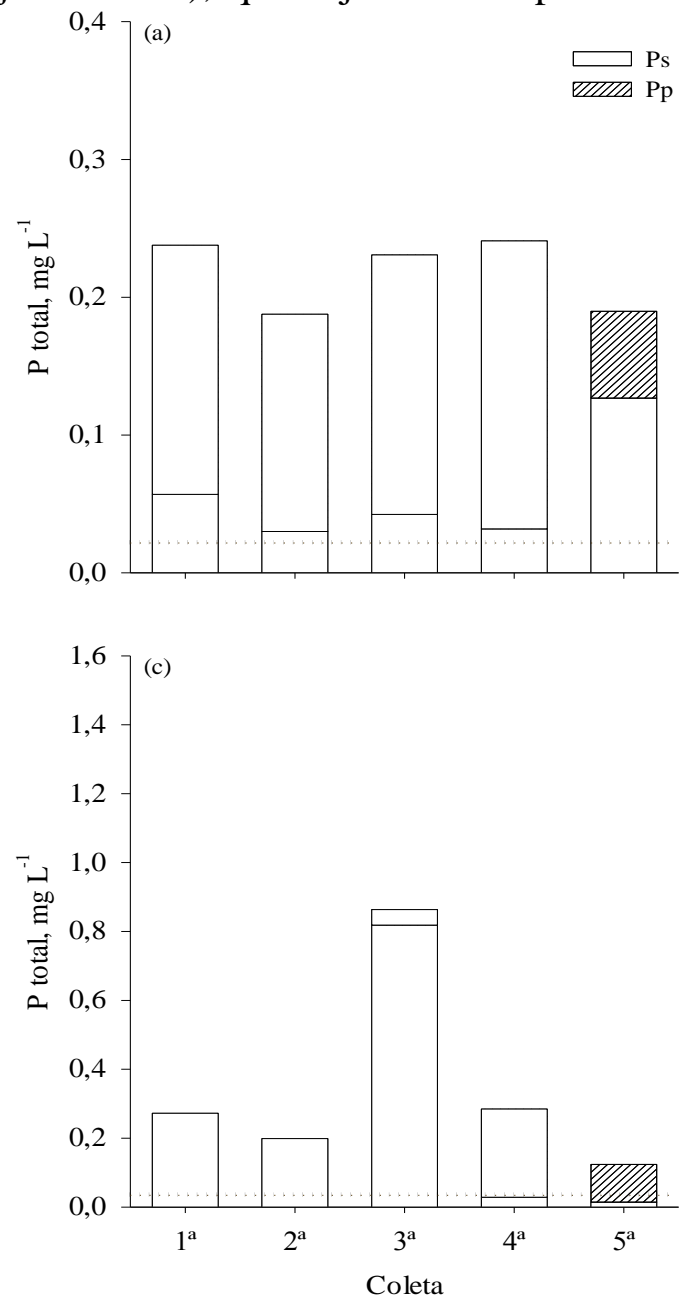

menores índices pluviométricos, que faz com que reduza o fluxo de água no solo e, consequentemente, a transferência de nutrientes. Nesse sentido, Buzelli e Cunha-Santino (2013), com o objetivo de avaliar e diagnosticar a qualidade da água no reservatório Barra Bonita, no período de estiagem e no período de cheia, através da utilização dos índices de qualidade das águas obtidos pelos relatórios de qualidade da água emitidos pela CETESB, no período de 2007 até 2011, destacando a importância da interpretação desses resultados, para a compreensão das possíveis fontes de degradação e comprometimento da qualidade da água, observaram redução nos teores de $\mathrm{P}$ total na água nos meses com menores índices pluviométricos, atribuindo este fato ao menor carreamento de formas particuladas e pelo menor fluxo de água no perfil do solo.
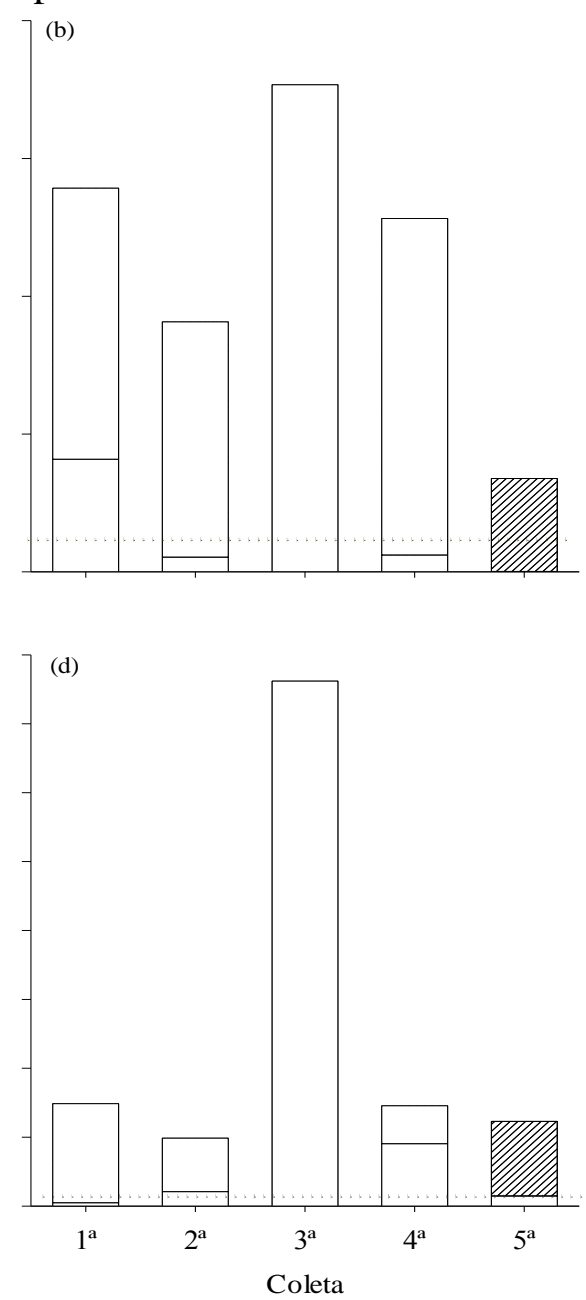

Figura 3. Teores de $\mathrm{P}$ total $\left(\mathrm{Ps}+\mathrm{Pp}\right.$ ) para os poços de abastecimento das propriedades 1 (a), 2 (b), 3 (c) e 4 (d). $1^{\mathrm{a}}$ coleta $=20 / 07 / 2015 ; 2^{a}$ coleta $=20 / 10 / 2015 ; 3^{a}$ coleta $=05 / 12 / 2015 ; 4^{a}$ coleta $=21 / 03 / 2016 ; 5^{a}$ coleta $=24 / 06 / 2016$.

Para os pontos PA2, PA3 e PA4 ocorreu predomínio da forma Ps, para a $3^{\mathrm{a}}$ coleta, apresentando correlação com os teores de $\mathrm{P}$ disponível no solo (Tabela 3). Nesse sentido, Gatiboni et al. (2008) afirmam que a fração inorgânica de $\mathrm{P}$ é aquela mais lábil e 
prontamente disponível no solo, acumulando-se, especialmente, nas camadas superficiais do solo e sendo aquela que apresenta maior poder de contaminação ambiental, pois pode sofrer processos de carreamento em eventos pluviométricos intensos.

$\mathrm{O} \mathrm{P}$ tem se tornado foco de estudos em decorrência do seu potencial contaminante de corpos hídricos, gerando quadros de eutrofização. O processo de eutrofização, ocorre quando o enriquecimento primário dos sistemas aquáticos (Aguiar et al., 2015). Dentre os fatores naturais que podem ocasionar a eutrofização, a dissolução de rochas, é um dos fatores que também afeta a disponibilidade de $\mathrm{P}$ no ambiente aquático, porém é uma ação natural, ocasionada pelo intemperismo químico das rochas (Gebler et al., 2012). Esse processo de aumento na quantidade de $\mathrm{P}$ ao ambiente aquático, em conjunto, com condições de luminosidade adequadas, faz com que, ocorra maior liberação de algas, diminuindo assim, o oxigênio dissolvido no meio, que por sua vez, ocasiona a morte dos organismos e liberação de material orgânico ao meio (Fia et al., 2009).

Os teores de $\mathrm{P}$ total obtidos nos pontos de estudo estabelecem um alerta para o manejo do solo que vem sendo desenvolvido nas áreas agrícolas das propriedades, pois mesmo não estando sobre influência direta da aplicação de DLS, ocorre presença de P na água utilizada para abastecimento. Conforme Conceição et al. (2014) a água subterrânea tem sido a fonte de água potável mais utilizada no mundo para abastecimento humano e o solo acima destes poços deve atuar como um filtro aos contaminantes que podem chegar a esses reservatórios e tornar a água imprópria para consumo. Nesse sentido, pode-se inferir que o solo acima desses poços não vem atuando como um filtro, mas sim, como possível fonte de $\mathrm{P}$ para a água.

\section{CONCLUSÕES}

A contaminação dos poços de abastecimento por nitrogênio aconteceu em duas das coletas realizadas. Isso demonstra a grande dinâmica do $\mathrm{N}$ no sistema solo, devendo o manejo dos dejetos, nesse caso, ser realizado através de maneira parcelada e em menores doses, favorecendo $\mathrm{o}$ aproveitamento do $\mathrm{N}$ pelas plantas e reduzindo as transferências para mananciais hídricos. Em relação ao P, todos os pontos avaliados apresentam-se contaminados, acelerando as condições de eutrofização. Além disso, há estreita relação entre os teores de P no solo com os teores observados na água, indicando que o monitoramento dos teores de $\mathrm{P}$ no solo pode ser um excelente indicativo de contaminação de mananciais hídricos.

\section{REFERENCIAS}

AGUIAR, C.P.O.; PELEJA, J.R.P.; SOUSA, K.N.S.; GOCH, Y.G.F.; GUIMARÃES, A.S. Nível de trofia em microbacias hidrográficas sob diferentes usos de solos, na região amazônica. Revista Brasileira de Recursos Hídricos, v. 20, n. 4, p. 1093-1102, 2015.

ALLOWAY, B.J. Heavy metals is soils. $2^{\text {a }}$ ed., Glasgow: Blackie Academic, 1995, $364 \mathrm{p}$

BASSO, C.J.; CERETTA, C.A.; DURIGON, R.; POLETTO, N.; GIROTTO, E. Dejeto líquido de suíno: II - perdas de nitrogênio e fósforo por percolação no solo sob plantio direto. Ciência Rural, v. 35, n. 6, p. 1305-1312, 2005.

CONAMA. Resolução no $\mathbf{3 5 7}$, de 17 de março de 2005. Dispõe sobre a classificação dos corpos de água e diretrizes ambientais para o seu enquadramento, bem como estabelece as condições e padrões de lançamento de efluentes, e dá outras providências. Disp. em: http://www.mma.gov.br/port/conama/res/res05/ res35705.pdf; acessado em 20/10/2015 às 11:11.

BUCCI, M.M.H.S.; DELGADO, F.E.F.; SANTOS, C.S.; OLIVEIRA, L.F.C. de Análise de metais, agrotóxicos, parâmetros físico-químicos e microbiológicos na represa Dr. João Penido, Juiz de Fora, MG. Revista Ambiente e Água, v. 10, n. 04, p. 805-824, 2015.

BUZELLI, G.M. \& CUNHA-SANTINO, M.B. da. Análise e diagnóstico da qualidade da água e estado trófico do reservatório Barra Bonita, SP. Revista Ambiente e Água, v. 8, n. 1, p. 186-205, 2013.
CAPOANE, V.; TIECHER, T.; SCHAEFER, G.L.; CIOTTI, L.H.; SANTOS, D.R. Transferência de nitrogênio e fósforo para águas superficiais em uma bacia hidrográfica com agricultura e pecuária intensiva no Sul do Brasil. Ciência Rural, v. 45, n. 04, p. 647-650, 2015.

CERETTA, C.A.; LORENSINI, F.; BRUNETTO, G.; GIROTTO, E.; GATIBONI, L.C.; LOURENZI, C.R.; TIECHER, T.L.; CONTI, L.; TRENTIN G.; MIOTTO, A.E. Frações de fósforo no solo após sucessivas aplicações de dejetos suínos em plantio direto. Pesquisa Agropecuária Brasileira, v. 45, n. 6, p. 593-602, 2010.

CONCEIÇÃO, F.T.; MAZZINI, F.; MORUZZI, R.B.; NAVARRO, G.R.B. Influências naturais e antrópicas na qualidade da água subterrânea de poços de abastecimento público na área urbana de Marília (SP). Revista Brasileira de Recursos Hídricos, v. 19, n. 3, p. 227-238, 2014.

CUCIO, M.S. \& PORTO, M.F.A. Carga máxima admissível de fósforo e estado trófico do Reservatório Tanque Grande, Guarulhos-SP. Revista Brasileira de Recursos Hídricos, v. 20, n. 3, p. 677-688, 2015.

FIA, R.; MATOS, A.T.; CORADI, P.C.; PEREIRA-RAMIREZ, O. Estado trófico na água na bacia hidrográfica da Lagoa Mirim, RS, Brasil. Revista Ambiente e Água, v. 4, n. 1, p. 132-141, 2009.

GATIBONI, L.C., BRUNETTO, G.; KAMINSKI, J.; RHENHEIMER, D.S.; CERETTA, C.A.; BASSO, C.J. 
Formas de Fósforo no solo após sucessivas adições de dejeto líquido de suínos em pastagem natural. Revista Brasileira de Ciência do Solo, v. 32, p. 1753-1761, 2008

GATIBONI, L.C.; SMYTH, T.J.; SCHMITT, D.E.; CASSOL, P.C.; OLIVEIRA, C.M.B. de Soil phosphorus threshold in evaluating risk of enviromental transfer to surface waters in Santa Catarina, Brazil. Revista Brasileira de Ciência do Solo, v. 39, n. 4, p. 1225-1234, 2015.

GEBLER, L.; BERTOL, I.; RAMOS, R.R.; LOUZADA, J.A.S.; MIQUELLUTI, D.J. Fósforo reativo: arraste superficial sob chuvas simuladas para diferentes coberturas vegetais. Revista Brasileira de Engenharia Agrícola e Ambiental, v. 16, n. 1, p. 99-107, 2012.

GIROTTO, E.; CERETTA, C.A.; LOURENZI, C.R.; LORENSINI, F.; TIECHER, T.L.; VIEIRA, R.C.B.; TRENTIN, G.; BASSO, C.J.; MIOTTO, A.; BRUNETTO, G. Nutrient transfer by leaching in a no-tillage system through soil treated with repeated pig slurry applications. Nutrient Cyclin in Agroecosystems, v. 95, p. 115-131, 2013.

GONZATTO, R.; MIOLA, E. C.C.; DONEDA, A.; PUJOL, S.B.; AITA, C.; GIACOMINI, S.J. Volatilização de amônia e emissão de óxido nitroso após aplicações de dejetos líquidos de suínos em solo cultivado com milho. Ciência Rural, v. 43, n. 9, p. 1590-1596, 2013.

GUARDINI, R.; COMIN, J.J.; SANTOS, D.R.; GATIBONI, L.C.; TIECHER, T.; SCHMITT, D.; BENDER, M.A.; FILHO, P.B.; OLIVEIRA, P.A.V.; BRUNETTO, G. Phosphorus accumulation and pollution potential in a Hapludt fertilized witg pig manure. Revista Brasileira de Ciência do Solo, v. 36, n. 4, p. 1333-1342, 2012.

MURPHY, J. \& RILEY, J.P. A modified single solution method for the determination oh phosphate in natural waters. Analytica Chimica Acta, v. 27, p. 31-36, 1962.

NOGUEIRA, D.J.; CASTRO, S.C.; DE SÁ, O.R. Avaliação da qualidade da água no reservatório UHE Furnas - MG, utilizando as brânquias de Pimelodus maculatus (LACÈPÉDE, 1803) como biomarcador de poluição ambiental. Revista Ciência et Praxis, v. 1, n. 1, p. 15 - 20, 2008.
PANDOLFO, C.M.; CERETTA, C.A.; MASSIGNAM, A.M.; VEIGA, M.; MOREIRA, I.C.L. Análise ambiental do uso de fontes de nutrientes associadas a sistema de manejo de solo. Revista Brasileira de Engenharia Agrícola e Ambiental, v. 12 , n. 5 , p. $512-519,2008$

PINTO, M.A.P.; FABBRIS, A.; BASSO, C.J.; SANTI, A.L.; GIROTTO, E. Aplicação de dejeto líquido de suínos e manejo do solo na sucessão aveia/milho. Pesquisa Agropecuária Tropical, v. 44, n. 2, p. 205-212, 2014.

PONTES, P.P.; MARQUES, A.R.; MARQUES, G.F. Efeito do uso e ocupação do solo na qualidade da água da micro-bacia do Córrego Banguelo - Contagem. Revista Ambiente e Água, v. 7, n. 3, p. 183-194, 2012.

SANTANA, L.M.; MORAES, M.E.B.; SILVA, D.M.L.; FERRAGUT, C. Spatial and temporal variation of phytoplankton in a tropical eutrophic river. Brazilian Journal Biology, v. 76, n. 3, p. 600-610, 2016.

SILVA, F.C. (Org.) Digestão nitroperclórica: manual de análises químicas de solos, plantas e fertilizantes. Brasília: Embrapa, 370p., 1999.

SILVA, M.C.A.; MONTEGGIA, L.O.; MIRANDA, L.A.; THEWES, M.R. Avaliação da viabilidade de utilização de colifagos como indicadores de poluição fecal: suas relações com parâmetros físicos e químicos e indicadores bacterianos. Revista Brasileira de Engenharia Sanitária e Ambiental, v. 20, n. 4, p. $645-652,2015$.

TEDESCO, M.J.; GIANELLO, C.; BISSANI, C.A.; BOHNEN, H.; VOLKWEISS, S.J. Análise de solo, plantas e outros materiais. Boletim Técnico n. 5, $2^{\mathrm{a}}$ ed. rev., Porto Alegre: Departamento de Solo, UFRGS, 174p., 1995 